\title{
Body Mass Index Categories and Attained Height in Portuguese Adults
}

\author{
Rafaela Rosário ${ }^{a, b}$ Renata Barros ${ }^{c}$ Patrícia Padrãoc, d Rute Santos ${ }^{e, f}$ \\ Vitor Hugo Teixeira ${ }^{c}$ Oscar Lopes ${ }^{g}$ Nelson Andrade ${ }^{c} \quad$ Andre Moreira $^{d, h}$ \\ Pedro Moreirac, $d$ \\ ${ }^{a}$ School of Nursing, University of Minho, Braga, Portugal; Research Center in Child Studies, \\ University of Minho, Braga, Portugal; ${ }^{C}$ Faculty of Nutrition and Food Sciences; University \\ of Porto, Porto, Portugal; ${ }^{d}$ Public Health Institute, Porto, Portugal; e Early Start Research \\ Institute, University of Wollongong, Wollongong, Australia; ${ }^{\mathrm{f}}$ Research Center in Physical \\ Activity, Health and Leisure, Faculty of Sport, University of Porto, Porto, Portugal; \\ ${ }^{9}$ Sport's Medical Center of Braga, Braga, Portugal; h' Faculty of Medicine, University of Porto, \\ Porto, Portugal
}

\section{Keywords}

Obesity · Adults · Body height

\begin{abstract}
Objective: To analyze the associations between height and BMI categories in a Portuguese representative sample. Methods: This is a cross-sectional study with a representative sample of 32,644 Portuguese adults (52.4\% females). Sociodemographic and lifestyle characteristics were obtained along with self-reported height and weight. We performed generalized linear models to assess the differences in attained height across BMI categories; analyses were adjusted for age, gender, education, family income per month, proxy reporting information, dietary patterns, and smoking. Results: BMI categories included underweight and normal weight (46.4\%), overweight (37.6\%), obese class I and II (15.2\%), and obese class III (0.8\%). Adults with normal weight had a significantly higher height (females $+7 \mathrm{~cm}$ and males $+5 \mathrm{~cm}$ ) when compared to obese class III. As BMI categories increased, height decreased. In females and males, after adjusting for confounders, estimates of attained height decreased when compared to the unadjusted model $(\beta=-0.049,95 \% \mathrm{Cl}=-0.050 ;-0.049$ and $\beta=-0.030,95 \%$ $\mathrm{Cl}=-0.031 ;-0.029$, respectively), although they remained still significant. Conclusion: Our results suggest a significant difference in attained height between BMI categories. Future intervention programs aiming at preventing overweight and obesity should monitor sociodemographic, health and environmental conditions that affect attained height potential.

(c) 2018 The Author(s)

Published by S. Karger $\mathrm{GmbH}$, Freiburg


Rosário et al.: Body Mass Index Categories and Attained Height in Portuguese Adults

\section{Introduction}

Obesity is a serious public health condition and is increasing all over the world $[1,2]$. It is known that besides the imbalance of energy intake and expenditure, other genetic, behavioral and environmental factors may contribute to the development of obesity [3,4].

BMI (weight $(\mathrm{kg}) /$ height $(\mathrm{m})^{2}$ ) is the most widely used anthropometric index in epidemiological studies as well as in clinical practice to classify peoples' weight status. Nevertheless, it is known that BMI is an imperfect indicator of weight distribution and body composition [5]. Whilst weight is a result of the balance of energy (intake and expenditure), height is considered an heritable human trait [6], influenced by environment, context, sociodemographic and economic determinants throughout life course $[7,8]$. Moreover, height is positively associated to wealth, success [9], and social status [7, 10] while is inversely associated with some biological and behavioral determinants of cardiovascular disease [11-13].

Height is a proxy indicator of nutritional well-being, and average height is conceptualized as the 'biological standard of living', in contrast to the concept of 'standard of living'. The latter is considered on a monetary perspective [10]. Taller people are also considered in advantage compared to shorter $[14,15]$. In Portugal, height has increased by about $0.99 \mathrm{~cm}$ per decade since the beginning of 20th century until 2000 , most likely due to an improvement in overall living conditions [16], in accordance to what has been observed in other southern European countries [15].

During growth, obese children are likely to be taller than their normal-weight peers and have an earlier onset of puberty [17]. However, these differences tend to attenuate during adolescence and in adulthood $[18,19]$. Additionally, there are associations between the age of puberty and anthropometric parameters in adulthood. Girls who have menarche at earlier ages have a reduced height and an increased risk of obesity in adulthood [20-22]. Although there is a high concern about obesity and height during childhood and adolescence [22, 23], research on height differences between weight status categories in adults is scarce. With this study, we address this knowledge gap by exploring the associations between the body height and BMI categories in a representative sample of Portuguese adults.

\section{Participants and Methods}

Participants and Study Design

This study gathered data from the Fourth Portuguese National Health Survey (NHS), developed by the National Institute of Statistics. Methodology of the NHS is described elsewhere [24]. Briefly, sampling procedures included the selection of participants from households during 2005 and 2006, using a multistage random probability design (hospitals, prisons, military houses, and community care institutions were excluded). A representative sample of 41,193 participants from all ages was gathered, distributed over the main Portuguese territorial units: North, Center, Lisbon, Alentejo, Algarve, and the archipelagos of Madeira and Azores. A primary sampling unit, based on the housing unit of the population census, was randomly selected within each territorial unit, and subjects living in the sampling unit were surveyed. Two levels were defined: the district (townships) and units geographically defined of 240 housings (within the district). The assessment was performed by trained interviewers and included a questionnaire about social and demographic characteristics, health, and chronic diseases (including obesity). The survey response rate was $76 \%$. Therefore, the present report includes a representative sample of 32,644 Portuguese adults.

Anthropometric, Sociodemographic and Dietary Patterns

Adults self-reported their height and weight, and BMI (weight $(\mathrm{kg}) /$ height $\left.(\mathrm{m})^{2}\right)$ was computed. BMI categories were defined according to the World Health Organization criteria [25]: underweight and normal weight (BMI $<25 \mathrm{~kg} / \mathrm{m}^{2}$ ), overweight (BMI between 25.0 and $29.9 \mathrm{~kg} / \mathrm{m}^{2}$ ), obese class I (BMI between 30.0 and $34.9 \mathrm{~kg} / \mathrm{m}^{2}$ ), class II (BMI between 35.0 and $39.9 \mathrm{~kg} / \mathrm{m}^{2}$ ) and class III (BMI $\geq 40.0 \mathrm{~kg} / \mathrm{m}^{2}$ ). In the analysis 
Rosário et al.: Body Mass Index Categories and Attained Height in Portuguese Adults

Table 1. Selected characteristics of the NHS Portugal ${ }^{\mathrm{a}}$

\begin{tabular}{|c|c|c|c|}
\hline & All $(n=32,644)$ & Females & Males \\
\hline Participants, \% & 100 & 52.4 & 47.6 \\
\hline Height, m & $1.64(0.09)$ & $1.59(0.07)$ & $1.70(0.08)$ \\
\hline Weight, kg & $70.1(13.3)$ & $65.2(12.2)$ & $75.9(11.9)$ \\
\hline BMI, $\mathrm{kg} / \mathrm{m}^{2}$ & $25.8(4.4)$ & $25.8(4.8)$ & $26.1(3.8)$ \\
\hline \multicolumn{4}{|l|}{ Age, years } \\
\hline $20-39$ & 37.8 & 35.9 & 39.9 \\
\hline $40-64$ & 40.5 & 40.1 & 41.1 \\
\hline $65-84$ & 19.8 & 21.6 & 17.7 \\
\hline$\geq 85$ & 1.9 & 2.5 & 1.3 \\
\hline \multicolumn{4}{|l|}{ Education } \\
\hline None & 12.7 & 16.6 & 8.3 \\
\hline Elementary school & 34.1 & 33.4 & 34.8 \\
\hline Middle school & 27.8 & 24.8 & 31.1 \\
\hline High school & 12.2 & 11.6 & 13.0 \\
\hline Tertiary education & 13.1 & 13.6 & 12.6 \\
\hline \multicolumn{4}{|l|}{ Family income per month, EUR } \\
\hline$\leq 500$ & 23.7 & 26.6 & 20.6 \\
\hline $501-1,200$ & 44.1 & 42.8 & 45.5 \\
\hline $1,201-2,000 €$ & 20.0 & 19.0 & 21.1 \\
\hline$>2,000$ & 12.2 & 11.6 & 12.8 \\
\hline Proxy reporting information & 29.8 & 21.1 & 39.2 \\
\hline \multicolumn{4}{|l|}{ BMI status } \\
\hline Underweight and normal weight & 46.4 & 50.2 & 42.2 \\
\hline Overweight & 37.6 & 33.0 & 42.5 \\
\hline Obesity classes I and II & 15.2 & 15.6 & 14.8 \\
\hline Obesity class III & 0.8 & 1.1 & 0.4 \\
\hline \multicolumn{4}{|l|}{ Physical activity } \\
\hline Low & 39.7 & 41.7 & 37.4 \\
\hline Moderate & 46.3 & 46.9 & 45.4 \\
\hline High & 3.2 & 11.3 & 17.1 \\
\hline \multicolumn{4}{|l|}{ Smoking } \\
\hline Non-smoker & 61.7 & 81.1 & 40.5 \\
\hline Current smoker & 21.4 & 12.0 & 31.8 \\
\hline Past smoker & 16.8 & 6.9 & 27.7 \\
\hline \multicolumn{4}{|l|}{ Dietary patterns } \\
\hline 'Dairy and fruit' & $-0.05(0.66)$ & $0.10(0.63)$ & $-0.22(0.65)$ \\
\hline 'Soup and starchy foods' & $-0.03(0.56)$ & $-0.06(0.57)$ & $0.01(0.55)$ \\
\hline 'High fat, sugar and salt' & $0.17(0.63)$ & $0.16(0.62)$ & $0.18(0.65)$ \\
\hline 'Fish, fruit and vegetable' & $0.01(0.58)$ & $0.03(0.58)$ & $-0.01(0.59)$ \\
\hline 'Sugary and fatty foods' & $0.02(0.50)$ & $0.03(0.51)$ & $0.01(0.50)$ \\
\hline
\end{tabular}

${ }^{a}$ Values are proportions (\%) unless for weight, height, BMI and dietary patterns which are mean (SD). Sample weighted pond 1.

of data, obesity classes I and II were merged (prevalence of $12.7 \%$ and $2.5 \%$, respectively) because of the latter low prevalence.

The NHS included information about participants' age, gender, level of education, family income per month, smoking habits, physical activity, and dietary patterns. Level of education included the following categories: none, elementary school (0-4 years), middle school (5-9 years), high school (10-12 years), and tertiary education (more than 12 years). The categories in relation to family income per month were defined as follows: <EUR 500; EUR 501-1,200; EUR 1,201-2,000; >EUR 2,000. Smoking habits were obtained as current smokers, past smokers, and non-smokers.

NHS dietary questionnaire included a list of 20 dichotomous questions ('Yesterday, did you consume any of the following foods?') about usual foods and beverages consumed at meals and snacks in the previous 
Rosário et al.: Body Mass Index Categories and Attained Height in Portuguese Adults

Table 2. Adult height according to obesity in a Portuguese representative sample

\begin{tabular}{|c|c|c|c|c|}
\hline \multirow[t]{2}{*}{ Weight status } & \multicolumn{2}{|l|}{ Female } & \multicolumn{2}{|l|}{ Male } \\
\hline & $\begin{array}{l}\text { unadjusted } \\
\text { mean (SD) }\end{array}$ & adjusted model & $\begin{array}{l}\text { unadjusted } \\
\text { mean (SD) }\end{array}$ & adjusted model \\
\hline Underweight + normal weight & $1.61(0.07)$ & ref & $1.72(0.08)$ & ref \\
\hline Overweight & $1.58(0.06)$ & $-0.008(-0.008 ;-0.008)^{* *}$ & $1.70(0.07)$ & $-0.010(-0.010 ;-0.010)^{* *}$ \\
\hline Obesity classes I and II & $1.57(0.07)$ & $-0.016(-0.016 ;-0.016)^{* *}$ & $1.68(0.08)$ & $-0.022(-0.022 ;-0.022)^{* *}$ \\
\hline Obesity class III & $1.54(0.10)$ & $-0.049(-0.050 ;-0.049)^{* *}$ & $1.67(0.12$ & $-0.030(-0.031 ;-0.029)^{* *}$ \\
\hline
\end{tabular}

Adjusted model: Generalized linear models adjusted for age, gender, weight status, education, family income, proxy reporting information, smoking and dietary patterns.

$* * \mathrm{p} \leq 0.001$.

day [26]. The list of foods and beverages included: milk and dairy; vegetable soup, vegetables and fruit; bread and cereal products; meat; fish; potatoes, rice and pasta; pulses; pastry, chocolates or sweet desserts at meals. Snacks included: fruit; bread or sandwiches; milk and dairy; juices and soft drinks; pastry, chocolates or sweet desserts; other candies; salty snacks; chips; and alcoholic beverages. Based on this list, five dietary patterns were defined by latent trait models, as described elsewhere [26, 27]. Briefly, the 'dairy and fruit' dietary pattern was positively correlated with fruit, milk, and dairy products. The 'soup and starchy foods' dietary pattern was positively correlated with vegetable soup, bread, and pulses. The dietary pattern 'high fat, sugar, and salt' was positively correlated with pastry, chocolate and sweet desserts, other candies, salty snacks, chips, fruit juices, soft drinks, and alcoholic beverages. The 'fish, fruit, and vegetables' dietary pattern was positively correlated with fish, vegetables, and fruit. The dietary pattern 'sugary and fatty foods' was positively correlated with, pastry, chocolate, and sweet desserts.

\section{Statistical Analysis}

Data is described as mean \pm standard deviation (SD) or proportions where appropriate, conducted with sampling weights. Student's t-tests, ANOVA, Mann Whitney U, Kruskal Wallis and chi square tests were used to compare variables between obesity, height, and confounder variables. Age, gender, education, family income per month, proxy reporting information, smoking, and dietary patterns were analyzed as confounders. Generalized linear models were used to estimate the associations between BMI categories and height among adults adjusted for the above-mentioned confounders.

A 0.05 level of significance and 95\% CI were considered. Data analysis was performed using IBM SPSS ${ }^{\circledR}$, version 23.0 (IBM, Armonk, NY, USA).

\section{Results}

The sociodemographic characteristics of the 32,644 participants are summarized in table 1. Most of the adults included in the sample were aged 40-64 years; females comprised $52.4 \%$ of the whole sample, and $46.8 \%$ of the participants had no formal education or only elementary education. Prevalence of underweight and normal weight was $46.4 \%$, of overweight $37.6 \%$, and of obesity $16.0 \%$.

In the analysis, average adult height decreased across BMI categories. Height was approximately $9 \mathrm{~cm}$ higher in underweight and normal-weight adults when compared to obese class III (table 2). The fully adjusted model confirmed the unadjusted analysis - a consistent difference between height and BMI categories although with an attenuation in the estimates for both males and females compared to the crude model. Normal-weight adults had a significantly higher height $(3.0 \mathrm{~cm}$ in males and $4.9 \mathrm{~cm}$ in females) when compared to the reference obese class III (table 2). 
Rosário et al.: Body Mass Index Categories and Attained Height in Portuguese Adults

\section{Discussion}

In this representative sample of Portuguese adults, normal-weight adults of both genders were significantly taller than their obese counterparts. Also, height decreased across BMI categories, independently of sociodemographic and lifestyle characteristics.

This is the first study that addressed associations between height and BMI categories in a representative sample of adults. This is particularly important because anthropometry is considered a proxy-measure of biological welfare [10], and height might be a variable of interest when analyzing obesity status in adults. Previous studies found that height and waist circumference were negatively correlated in both genders, although this association was weaker in females [5]. This study contributes further insights concerning attained height and obesity and provides some clues for further investigations in the domain of height patterns and obesity risk. Previous studies found that stunted children had an impaired fat oxidation compared with non-stunted children, but had a greater likelihood to excess weight gain [28]. In contrast, high body fat in girls was associated with an earlier onset of puberty $[29,30]$, which in turn was negatively associated with attained height and increased likelihood of overweight and obesity in adulthood [22, 31,32]. Other studies are a mirror of similar negative associations between BMI and growth during adolescence [33].

The trends of height in worldwide is heterogeneous, and it seems that there is a discrepancy between height and obesity in the last decades [15]. France and Singapore had the largest height gain, whereas the US had the smallest height gain of all countries analyzed [15]. Additionally, the US had a higher increase of obesity compared to a stagnation of height [10]. In Europe, taller people are found in the northern countries, namely in the Netherlands [15], the same country that has the lowest prevalence of obesity [1]. In the last century, Portugal had an average increase of $8.93 \mathrm{~cm}$ in males' height [16]. Moreover, there was an increase in the prevalence of overweight and obesity, being more pronounced between 1995 and 2000 [34], that continued until today [35].

Nutritional status is considered to be important from the prenatal to the postnatal period and for at least 2 years of age. Nevertheless, in health care settings, it may be difficult to identify stunting, particularly where short stature is the norm [36].

This study has several strengths that should be acknowledged. First, we used a representative sample of Portuguese adults from both genders to analyze the associations between height and BMI categories. Second, we performed an analysis accounting for important lifestyle and socioeconomic confounders, such as income per month. Previous studies found a positive correlation between growth and income [37], and we used this variable in order to minimize bias. Third, we performed the analysis according to gender. It is well known that women and men grow differently, and globally women are shorter than men [15]. In this study there was a similar tendency regarding height and categories of obesity in both genders. In addition, the NHS included important sociodemographic and lifestyle confounders of obesity such as age, gender, education, family income per month, smoking, proxy reporting information, and dietary patterns.

This study is not without limitations. First, weight and height were self-reported, and it is not possible to exclude recall bias. Previous studies found that self-reported height may be overestimated by older people [38], in contrast to self-reported weight which may be underestimated by men and women [39]. Second, BMI was used to define categories of obesity; however, this anthropometric index does not allow to discriminate the contribution of fat mass and fat-free mass. Third, dietary intake was collected based on a checklist of foods and beverages intake in the previous $24 \mathrm{~h}$. This could be considered less accurate than questionnaires, which take into account the frequency, portion size, variety, and other foods and beverages outside the list. Although the NHS included physical activity, it is only available in 
$14 \%$ of the participants. As it is not possible to generalize these data to the whole sample, we did not include them in the models. Nonetheless, the results followed the same tendency when adjusting for physical activity. Attained height in obese adults was $4.2 \mathrm{~cm}$ lower than in normal-weight subjects $(\beta=0.042,95 \%$ CI $0.021 ; 0.063$, data shown in a supplementary table, available at http://content.karger.com/ProdukteDB/produkte.asp?doi=491754). Finally, the study is cross-sectional, and we are unable to establish causal relationships. Further research is needed with cross-sectional and longitudinal data in order to confirm or rule out our findings.

\section{Conclusion}

Normal-weight adults are significantly taller than their overweight and obese counterparts, independently of sociodemographic and lifestyle characteristics. This study shows not only the potential of height as an anthropometric indicator of overweight and obesity prevalence but also its likely relevance in obesity prevention programs. Monitoring economic, social, political, and environmental systems that propitious the physical growth is recommended, so that human beings can attain their height potential.

\section{Disclosure Statement}

The authors declare they have no conflict of interests to declare.

\section{References}

1 Ng M, Fleming T, Robinson M, Thomson B, Graetz N, Margono C, Mullany EC, Biryukov S, Abbafati C, Abera SF, Abraham JP, Abu-Rmeileh NM, Achoki T, AlBuhairan FS, Alemu ZA, Alfonso R, Ali MK, Ali R, Guzman NA, Ammar W, Anwari P, Banerjee A, Barquera S, Basu S, Bennett DA, Bhutta Z, Blore J, Cabral N, Nonato IC, Chang JC, Chowdhury R, Courville KJ, Criqui MH, Cundiff DK, Dabhadkar KC, Dandona L, Davis A, Dayama A, Dharmaratne SD, Ding EL, Durrani AM, Esteghamati A, Farzadfar F, Fay DF, Feigin VL, Flaxman A, Forouzanfar MH, Goto A, Green MA, Gupta R, Hafezi-Nejad N, Hankey GJ, Harewood HC, Havmoeller R, Hay S, Hernandez L, Husseini A, Idrisov BT, Ikeda N, Islami F, Jahangir E, Jassal SK, Jee SH, Jeffreys M, Jonas JB, Kabagambe EK, Khalifa SE, Kengne AP, Khader YS, Khang YH, Kim D, Kimokoti RW, Kinge JM, Kokubo Y, Kosen S, Kwan G, Lai T, Leinsalu M, Li Y, Liang X, Liu S, Logroscino G, Lotufo PA, Lu Y, Ma J, Mainoo NK, Mensah GA, Merriman TR, Mokdad AH, Moschandreas J, Naghavi M, Naheed A, Nand D, Narayan KM, Nelson EL, Neuhouser ML, Nisar MI, Ohkubo T, Oti SO, Pedroza A, Prabhakaran D, Roy N, Sampson U, Seo H, Sepanlou SG, Shibuya K, Shiri R, Shiue I, Singh GM, Singh JA, Skirbekk V, Stapelberg NJ, Sturua L, Sykes BL, Tobias M, Tran BX, Trasande L, Toyoshima H, van de Vijver S, Vasankari TJ, Veerman JL, Velasquez-Melendez G, Vlassov VV, Vollset SE, Vos T, Wang C, Wang X, Weiderpass E, Werdecker A, Wright JL, Yang YC, Yatsuya H, Yoon J, Yoon SJ, Zhao Y, Zhou M, Zhu S, Lopez AD, Murray CJ, Gakidou E: Global, regional, and national prevalence of overweight and obesity in children and adults during 1980-2013: a systematic analysis for the Global Burden of Disease Study 2013. Lancet 2014;384:766-781.

-2 NCD Risk Factor Collaboration (NCD-RisC): Trends in adult body-mass index in 200 countries from 1975 to 2014:a pooled analysis of 1698 population-based measurement studies with 19.2 million participants. Lancet 2016;387:1377-1396.

-3 Dirinck EL, Dirtu AC, Govindan M, Covaci A, Van Gaal LF, Jorens PG: Exposure to persistent organic pollutants: relationship with abnormal glucose metabolism and visceral adiposity. Diabetes Care 2014;37:1951-1958.

4 Heindel JJ, Newbold R, Schug TT: Endocrine disruptors and obesity. Nat Rev Endocrinol 2015;11:653-661.

$\checkmark 5$ Wells JC, Treleaven P, Cole TJ: BMI compared with 3-dimensional body shape: the UK National Sizing Survey. Am J Clin Nutr 2007;85:419-425.

6 Lettre G: Recent progress in the study of the genetics of height. Hum Genet 2011;129:465-472.

7 Komlos J, Kriwy P: Social status and adult heights in the two Germanies. Ann Hum Biol 2002;29:641-648.

-8 Silventoinen K, Kaprio J, Lahelma E, Koskenvuo M: Relative effect of genetic and environmental factors on body height: differences across birth cohorts among Finnish men and women. Am J Public Health 2000;90: 627-630. 
Subramanian SV, Ozaltin E, Finlay JE: Height of nations: a socioeconomic analysis of cohort differences and patterns among women in 54 low- to middle-income countries. PLoS One 2011;6:e18962.

10 Komlos J, Baur M: From the tallest to (one of) the fattest: the enigmatic fate of the American population in the 20th century. Econ Hum Biol 2004;2:57-74.

11 Jousilahti P, Tuomilehto J, Vartiainen E, Eriksson J, Puska P: Relation of adult height to cause-specific and total mortality: a prospective follow-up study of 31,199 middle-aged men and women in Finland. Am J Epidemiol 2000;151:1112-1120.

-12 Emerging Risk Factors Collaboration: Adult height and the risk of cause-specific death and vascular morbidity in 1 million people: individual participant meta-analysis. Int J Epidemiol 2012;41:1419-1433.

13 Paajanen TA, Oksala NK, Kuukasjarvi P, Karhunen PJ: Short stature is associated with coronary heart disease: a systematic review of the literature and a meta-analysis. Eur Heart J 2010;31:1802-1809.

-14 Tyrrell J, Jones SE, Beaumont R, Astley CM, Lovell R, Yaghootkar H, Tuke M, Ruth KS, Freathy RM, Hirschhorn JN, Wood AR, Murray A, Weedon MN, Frayling TM: Height, body mass index, and socioeconomic status: Mendelian randomisation study in UK Biobank. Bmj 2016;352:i582.

15 NCD Risk Factor Collaboration (NCD-RisC): A century of trends in adult human height. Elife 2016;5.

16 Padez C: Secular trend in stature in the Portuguese population (1904-2000). Ann Hum Biol 2003;30:262-278.

17 Vignolo M, Naselli A, Di Battista E, Mostert M, Aicardi G: Growth and development in simple obesity. Eur J Pediatr 1988;147:242-244.

18 De Simone M, Farello G, Palumbo M, Gentile T, Ciuffreda M, Olioso P, Cinque M, De Matteis F: Growth charts, growth velocity and bone development in childhood obesity. Int J Obes Relat Metab Disord 1995;19:851-857.

19 He Q, Karlberg J: BMI in childhood and its association with height gain, timing of puberty, and final height. Pediatr Res 2001;49:244-251.

-20 Biro FM, McMahon RP, Striegel-Moore R, Crawford PB, Obarzanek E, Morrison JA, Barton BA, Falkner F: Impact of timing of pubertal maturation on growth in black and white female adolescents: the National Heart, Lung, and Blood Institute Growth and Health Study. J Pediatr 2001;138:636-643.

-21 Okasha M, McCarron P, McEwen J, Smith GD: Age at menarche: secular trends and association with adult anthropometric measures. Ann Hum Biol 2001;28:68-78.

-22 Stein AD, Lundeen EA, Martorell R, Suchdev PS, Mehta NK, Richter LM, Norris SA: Pubertal development and prepubertal height and weight jointly predict young adult height and body mass index in a prospective study in South Africa. J Nutr 2016;146:1394-1401.

-23 Murasko JE: A Longitudinal study of income differences in the height-BMI relation among U.S. children ages 6 to 14. Biodemography Soc Biol 2016;62:235-248.

24 Moreira P, Moreira A, Padrao P, Delgado L: The role of economic and educational factors in asthma: evidence from the Portuguese health survey. Public Health 2008;122:434-439.

-25 World Health Organization: Obesity: Preventing and Managing the Global Epidemic. Report of a WHO Consultation. Geneva, WHO Technical Report Series No 894, 2000.

-26 Barros R, Moreira A, Padrao P, Teixeira VH, Carvalho P, Delgado L, Lopes C, Severo M, Moreira P: Dietary patterns and asthma prevalence, incidence and control. Clin Exp Allergy 2015;45:1673-1680.

27 Barros R, Moreira P, Padrao P, Teixeira VH, Carvalho P, Delgado L, Moreira A: Obesity increases the prevalence and the incidence of asthma and worsens asthma severity. Clin Nutr 2017;36:1068-1074.

-28 Hoffman DJ, Sawaya AL, Verreschi I, Tucker KL, Roberts SB: Why are nutritionally stunted children at increased risk of obesity? Studies of metabolic rate and fat oxidation in shantytown children from Sao Paulo, Brazil. Am J Clin Nutr 2000;72:702-707.

29 Kaplowitz PB: Link between body fat and the timing of puberty. Pediatrics 2008;121(suppl 3):S208-217.

-30 Wang Y: Is obesity associated with early sexual maturation? A comparison of the association in American boys versus girls. Pediatrics 2002;110:903-910.

-31 Freedman DS, Khan LK, Serdula MK, Dietz WH, Srinivasan SR, Berenson GS: The relation of menarcheal age to obesity in childhood and adulthood: the Bogalusa heart study. BMC Pediatr 2003;3:3.

-32 van Lenthe FJ, Kemper CG, van Mechelen W: Rapid maturation in adolescence results in greater obesity in adulthood: the Amsterdam Growth and Health Study. Am J Clin Nutr 1996;64:18-24.

-33 Komlos J, Breitfelder A: Are Americans shorter (partly) because they are fatter? A comparison of US and Dutch children's height and BMI values. Ann Hum Biol 2007;34:593-606.

-34 Carreira H, Pereira M, Azevedo A, Lunet N: Trends of BMI and prevalence of overweight and obesity in Portugal (1995-2005): a systematic review. Public Health Nutr 2012;15:972-981.

-35 Sardinha LB, Santos DA, Silva AM, Coelho-e-Silva MJ, Raimundo AM, Moreira H, Santos R, Vale S, Baptista F, Mota J: Prevalence of overweight, obesity, and abdominal obesity in a representative sample of Portuguese adults. PLoS One 2012; 7:e47883.

36 de Onis M, Branca F: Childhood stunting: a global perspective. Matern Child Nutr 2016;12(suppl 1):12-26.

-37 Barker DJ, Eriksson JG, Forsen T, Osmond C: Infant growth and income 50 years later. Arch Dis Child 2005; 90: 272-273.

-38 Kuczmarski MF, Kuczmarski RJ, Najjar M: Effects of age on validity of self-reported height, weight, and body mass index: findings from the Third National Health and Nutrition Examination Survey, 1988-1994. J Am Diet Assoc 2001;101:28-34; quiz 35-26.

39 Connor Gorber S, Tremblay M, Moher D, Gorber B: A comparison of direct vs. self-report measures for assessing height, weight and body mass index: a systematic review. Obes Rev 2007;8:307-326. 